\title{
Foundation phase science teacher identity: Exploring evolutionary module development to promote science teaching self-efficacy
}

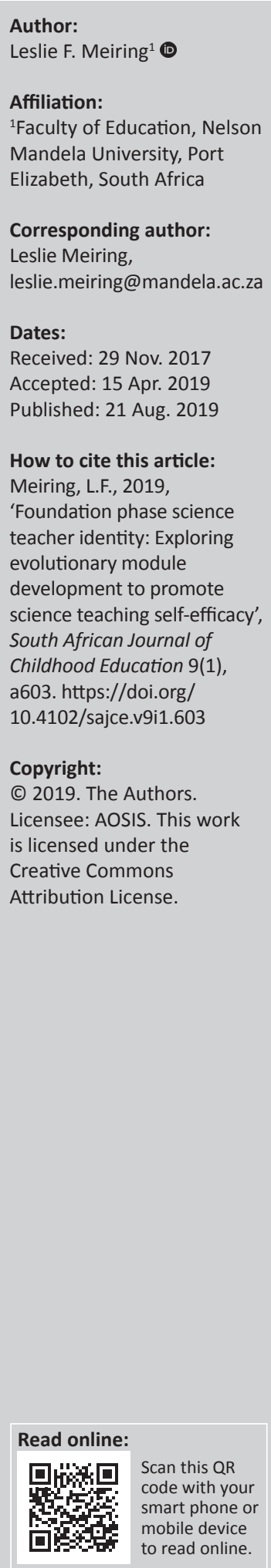

Background: The South African national school curriculum for the foundation phase (6- to 9-year-olds) does not have a unique subject called 'science', but 'hidden' away in the subject 'life skills', one detects a great deal of science, but not all of it overtly presented. This presents a challenge to teachers who might be limited in their science content knowledge and lack understanding of the processes of science, both of which might contribute to low levels of science teaching self-efficacy.

Aim: This article explores an evolutionary module development process designed to promote science teaching self-efficacy.

Setting: Pre-service foundation phase student teachers taking a single method module in science.

Methods: The study is anchored within the Scholarship of Teaching and Learning (SoTL). On completion of the module, student teachers complete anonymous module-evaluation questionnaires. An interpretive, qualitative approach is used to support discussion of the module's principles, content and delivery within the context of module development.

Results: Data originate from two cohorts of student teachers (2011 and 2014). These data inform lecturers' decisions on the re-development of the module for the following year. The intervening years (2012-2013) saw the module being firmly anchored on three pillars, namely teacher identity, science teaching self-efficacy and the nature of science.

Conclusion: This article outlines the evolution of a pre-service foundation phase science module, from a science-content-only module (2006) through to a module whose underpinning principles and content attempt to address the hopes, fears and challenges faced by prospective foundation phase teachers.

Keywords: science teacher identity; self-efficacy; foundation phase science teaching; nature of science; scientific enquiry.

\section{Introduction and background}

The foundation phase (FP) consists of the first 4 years (Grade R - Grade 3) of schooling in South Africa (Department of Basic Education 2011). This is where learners get exposed to science and where their '... love for science should start and be nurtured so that they develop a curiosity about the world and become critical thinkers' (Beni, Stears \& James 2017:1). Palmer (2006) concludes that a good understanding of content and pedagogy is required for teaching successfully. He did, however, identify primary science teachers as one group where this is a challenge. This suggests that FP teachers might not be sufficiently empowered to facilitate the development of the skills and subject knowledge required to teach science in the FP. One might reasonably expect a curriculum to support teachers, but according to Beni et al. (2017), the curriculum does not provide sufficient guidance on the types of activities, neither does it provide guidance on how to integrate the science within the rest of the curriculum programme. Bosman (2009) concurs that the relevant policy documents do not provide any, or sufficient, guidance for the FP teacher on how to actually teach the prescribed topics and skills. While in-service teachers tend to be positive about science, they 'are often ignorant and uncertain about what is required of them' (Bosman 2009:238). The key to successful FP science teaching, according to Bosman (2009:235-236), lies with teacher training. She proposed that training programmes should be able to provide teachers with 'adequate knowledge and skills in content, curriculum requirements, and in appropriate methodologies ...'. During the period 2006-2011, these three aspects of 
science teaching were also our focus areas. We now argue that this is not enough to enhance teachers' science teaching self-efficacy. The science component of FP initial education programmes need to include three additional and fundamental constructs: science teacher identity, self-efficacy and the nature of science (NOS). All three might meaningfully influence FP science teachers' praxis.

The FP curriculum does not have a unique subject called science, but 'hidden' away in the subject, life skills, one can detect a great deal of science (Department of Basic Education 2011). A perennial challenge for the science education specialist is that FP pre-service students don't like science. Palmer (2006) identified that negative school science experiences mitigated against the development of a high science teaching self-efficacy. At the start of a pre-service FP science module, it is not uncommon for lecturers to be confronted by some students who 'hate' science. This aversion to science appears to stem mainly from students' previous school experiences of the subject.

Each year a 6-month, 10-credit, introductory science module is taken by FP pre-service student teachers at our university. This is the only exposure to science that these students get during their 4-year BEd programme. When first introduced in 2006, the module contained only science content knowledge. The chosen content was that which is contained in the national senior phase school curriculum. This naive and unidimensional perception of what science an FP preservice student 'needs' to know about science appeared to make little or no difference in their attitude towards science. Apart from enabling students to answer simple, basic grade 9 school-level science examination questions, there appeared little gain of in-depth science content knowledge nor a change in attitudes towards science teaching. Roth (2014) sums up what we were becoming aware of during these initial forays into preparing FP science teachers:

\footnotetext{
... teachers lack the science content knowledge needed to teach science effectively, have little training in science-specific pedagogy, and have even less training in the scientific disciplines they are expected to teach. (p. 362)
}

Realising that if we were to succeed in positively changing FP teachers' science teaching efficacy, we needed to change the module's science content-only approach. Palmer (2006:337) claims that 'cognitive pedagogical mastery' has the potential to enhance self-efficacy. With this in mind, we spent the following 8 years adapting the module's curriculum. The curriculum morphed from being a science-content-based one, through a period in which, while still retaining large doses of 'pure' science content, and started shifting towards a more multi-faceted approach that included many hands-on activities. Additionally, we shifted the focus towards scientific literacy and finally to its present format as reported on in this article.

Identifying what science content knowledge is required is a good starting point. Making lectures interesting, topical, relevant, hands-on and using an engaging style (pops, bangs and science 'magic') are all relevant, but pre-service FP teachers need more than this. Roth (2014) encapsulates our 'aha' moment when she claims that:

Teachers engage students in hands-on science activities without linking those effectively to science ideas and practice. At best, we can hope that elementary teachers' desire to make science interesting for children will engage and maintain children's interest and identity in science. But this is not enough to meet society's needs for science literacy. (p. 363)

The first activity completed by pre-service FP teachers taking our science module is to complete a survey questionnaire. The questionnaire items range from reflecting on their school science experiences through to their feelings and expectations of the module. On discovering that they will have to teach a great deal of science, they express a range of emotions ranging from trepidation (experienced by the majority) through to excitement (see Figure 1). This scenario suggested three pillars on which to anchor the science module, namely: teacher identity (Avraamidou 2014; Luehmann 2007), science teaching self-efficacy (Evans 2015) and the NOS (Akerson, Abd-El-Khalick \& Lederman 2000). This article outlines how these three concepts informed the module's topics, hands-on activities and lecturer pedagogy, so as to develop confident, competent teachers who felt at home when integrating scientific enquiry, in the form of explorations (Johnston 2005).

\section{Literature review}

Students who enrol in FP education programmes are required to identify themselves as specialist FP teachers in three subjects: language, mathematics and life skills (Department of Basic Education 2011). Additionally, the life skills curriculum includes four study areas: beginning knowledge, personal and social well-being, creative arts and physical education. This subject focuses on the skills, concepts and values inherent in early childhood development and lays a foundation for the subjects taught in grades 4-12 (Department of Basic Education 2011). The introduction of life skills as a subject enjoined FP teachers to become experts in a whole range of subjects (Stroebel, Hay \& Bloemhoff 2017). It is in the beginning knowledge area where students need to identify themselves as both social sciences (history and geography) and natural sciences and technology experts. The challenge is

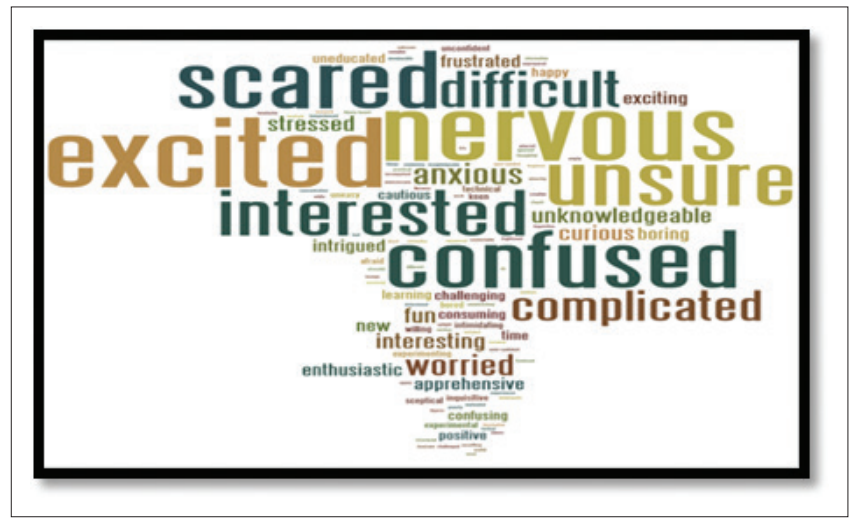

FIGURE 1: Sample of an initial word cloud. 
that each study area comes with its own constructs in the form of learning outcomes, content and skills and requires a robust understanding of the nature of the subject. Beni et al. (2017) posit that FP teachers might not see the need, or even desire, to identify themselves as anything other than an FP specialist. Being a subject specialist entails more than one's perception of identity, it involves a certain degree of subject knowledge and a perception of one's ability to teach that subject, which is, teaching self-efficacy (Woolhouse \& Cochrane 2010).

\section{Science teacher identity}

Avraamidou's (2014) definition of identity includes not only skills, knowledge attitudes, values and beliefs but also how these play out in specific contexts. Fortunately, identity is not fixed; it is constantly being moulded by interactions with other people, contexts and experiences. Changing teaching identity, however, involves risk, requiring engagement in a discourse that is unfamiliar, testing new areas of knowledge where the teacher might lack confidence in her ability to teach effectively (Avraamidou 2014; Slavin et al. 2014). Enhancing FP teachers' science content knowledge appears to be a good starting point for positively influencing FP teachers' science identity. Luehmann (2007), however, argues that teachers who want to value and engage in authentic science teaching need more than just science knowledge and skills; they need to develop a new professional identity of a 'real' science teacher. While acknowledging the centrality of science knowledge and skills in identifying oneself as a science teacher, one should not lose sight of the other aspects of science teacher identity, including beliefs about science teaching and personal science teaching efficacy (i.e. how one views oneself as an effective science teacher).

\section{Self-efficacy}

Tschannen-Moran, Hoy and Hoy (1998:233) define selfefficacy as 'the teacher's belief in his or her capability to organise and execute courses of action required to successfully accomplish a specific teaching task in a particular context'. Bandura (1997) proposed four main sources of self-efficacy. Firstly, enacted mastery experiences, where success in doing something promotes self-efficacy. In science, the mastery of hands-on science activities promotes science teaching self-efficacy (Mansfield \& WoodsMcConney 2012). Secondly, vicarious experiences, where one attempts to compare and align one's capability to a real or abstract model (Palmer 2006). Thirdly, verbal persuasion, involving positive feedback. Fourthly, physiological and affective status, which, according to Palmer (2006), revolves around how one responds to stress and fear in a particular situation. In a somewhat different interpretation of Bandura's four sources of self-efficacy, Mansfield and Woods-McConney (2012) claim that previously held beliefs and exposure to science both play a role in the development of science teaching self-efficacy. They claim that pre-service experiences, be they mastery at doing hands-on activities, being exposed to 'good' science teaching, receiving positive feedback and believing that they can actually do science, have profound influence right through pre-service teachers' careers. When working with pre-service teachers, one should be cognisant that self-efficacy is not fixed and that pre-service experiences can influence teachers' instructional practice. In her seminal study on the teaching of FP science in South Africa, Bosman (2009) found that FP teachers tended to avoid teaching science in their classrooms because of their lack of science content knowledge. Sandholtz and Ringstaff (2014) lament that teachers who have low levels of science teaching self-efficacy downplay teaching science, resulting in a disservice to young children who are ready and eager to engage in science. On the other hand, Roth (2014) said that when teachers do teach science, they concentrate on enjoyment, with little attention given to developing conceptual understanding in children. This, she suggests, might be because teachers lack confidence in their personal conceptual understanding of science. Effective science teaching involves more than just enjoyment and fun science; it involves children being actively engaged, resulting in them having a conceptual understanding of the science being taught (Konstantopoulos \& Chung 2011). Engaged teaching for conceptual understanding of science requires deploying a whole range of different and innovative teaching strategies. This, according to Sandholtz and Ringstaff (2014), requires confident science teachers. They report that when there is an increase in science teaching self-efficacy, there is a shift from a teacher- and textbook-centred focus to a more learner-centred approach, with its concomitant inquiry-based emphasis. A primary aim of science method courses should therefore be to promote science teaching self-efficacy. Sandholtz and Ringstaff (2014) recommend that pre-service early-years science teachers should be taught conceptually challenging science using a pedagogy that is appropriate for young children.

The national school curriculum for life skills uses topics or themes integrated into different study areas (Department of Basic Education 2011). Ideally, FP is taught by integrating all the beginning knowledges (i.e. social sciences, natural sciences and technology) into different topics. This, however, is fraught with problems, in that Beni et al. (2017) found that teachers have a really poor understanding of integration and that the science appears to be 'hidden' in the curriculum. It is this latter point that drove a participant in their study to exclaim: 'You see if I was science driven as a teacher then maybe I will pick up the aspects of science easier, but because I am not, it is hard to find it' (Beni et al. 2017:5). What mitigates against FP teachers focussing on making science an integral and central part of their instructional menu might be the mismatch between an enhanced teaching self-efficacy in languages and mathematics versus a low science teaching self-efficacy. If, however, teachers are able to positively advance their science teaching self-efficacy beliefs, there emerge teachers who possess a better balance between their perceptions of themselves as FP experts and their ability to teach science. The resulting change in their pedagogy with respect to science can then be ascribed to a change in science teaching self-efficacy 
(Sandholtz \& Ringstaff 2014:749). The core elements of science in the life skills curriculum are scientific process skills of exploration, enquiry and investigation. All three of the foregoing involve, to a greater or lesser extent, observing, comparing, classifying, measuring, experimenting and communicating (Department of Basic Education 2011). Johnston (2005) claims that the process of exploration should be the focus of young children's early science. All these skills are inexorably linked to the NOS, thus begging the question 'So what is science?'.

\section{The nature of science}

The NOS refers to a particular way of knowing and thinking in and about science and includes values and beliefs. This impacts on and influences the development of scientific knowledge (Akerson et al. 2000). Thus, an understanding of the NOS is fundamental to supporting the main aim of science education, which is to promote science as way of understanding the world around us. This understanding does, however, involve a good grasp of how scientific knowledge is constructed (Luehmann 2007). A robust understanding of the NOS by prospective science teachers becomes important for their science teaching. A number of studies highlight the claim that teachers' praxis in the classroom directly influences children's learning (Akerson et al. 2000). In their study of an elementary (primary school) science method course, Akerson et al. (2000:295) investigated the influence of a 'reflective, explicit, activity-based approach to nature of science'. Their study focused on the following aspects of NOS, namely:

- the empirical, tentative, subjective (theory-laden) nature of the scientific endeavour

- its imaginative and creative aspects

- the social and cultural aspects of the science

- the difference between observation and inference as science process skills

- the relationship between scientific theories and laws (Akerson et al. 2000:295).

The above suggests that science is more than an enjoyable, captivating and motivating activity. Zangori, Forbes and Biggers (2013) claim that fun hands-on science activities, without foregrounding scientific sense making, are a consequence of teachers simply not having a robust understanding of the NOS and scientific reasoning. This, they suggest, does a disservice to young children who have the capacity to engage in science as a sense-making exercise in their attempts at understanding the world. During a pre-service science method module, one can adopt an implicit approach to the NOS, by assuming that student teachers would come to an understanding of the NOS as a matter of course. On the other hand, one can take an explicit approach, similar to Akerson et al. (2000). They attempted an explicit approach to the NOS within a pre-service science method course, claiming that this approach benefited teachers in their actual classroom praxis. As such, not inducting FP pre-service teachers into the NOS might present problems for them when they start to teach in schools.

\section{Research design}

During the period (2006-2010), data sourced via anonymous online (MOODLE) module evaluations suggested that certain aspects of the module were perceived by students to be effective, while other aspects were problematic. The primary purpose of this data collection is to get students' views on the module so that the content and delivery can respond directly to students' responses. At the end of each of these years, the module was adapted to take this feedback into consideration (e.g. more hands-on activities were introduced the following year). It was during 2010 that the module started to undergo a radical revision, shifting from content-focus towards a focus on the pre-service teacher and their views and attitudes towards science.

Maurer and Law (2016), while acknowledging Kathleen McKinney's 2015 view that there remains a lack of consensus on a single definition for the Scholarship of Teaching and Learning (SoTL), used her 2003 and 2006 writings to clarify the difference between good teaching, scholarly teaching and SoTL. Good teaching enables learning, something which we were trying to achieve in the period 2006-2010. Scholarly teaching uses evidence from teaching and learning, coupled with best practice, to enhance learning. This is the approach we have followed post 2010. This article takes its cue from SoTL, where evidence-based innovations in teaching and learning are reported on and disseminated for colleagues in similar fields to use in their scholarly teaching.

This study reports on the period 2011 to 2014. It was during this period that the module was changed to focus on pre-service teacher's identity as a science teacher, with a concomitant emphasis on enhancing science teacher self-efficacy, all within the ambient of explicitly teaching about the NOS.

Data were collected via an initial pre-module and then again using a post-module questionnaire. Two data sets were reported on, namely: 2011 and 2014. It was during this 3-year period that the module underwent continuous adaptations, spurred on by what students were telling us and what we were learning about the teaching of science to these preservice FP teachers. These two data sets were chosen as they best suggest how changes in a module philosophy, from a content hands-on activity driven module (2011) through to a more student teacher and science as a discipline approach (2014), influence the FP pre-service teachers' perceptions of science and of themselves as science teachers.

\section{Research question}

Scholarship of Teaching and Learning requires one to reflect on one's teaching and then identify what actions or situations will improve that teaching and learning. With this in mind, 
one has to formulate the question that underpins this reflection and as such the research question driving this study is:

How can a science method module, premised on teacher identity, self-efficacy and the NOS, positively influence FP pre-service students' science teaching self-efficacy?

\section{Methods}

This study is situated in the SoTL, where evidence-based reflections on a specific teaching and learning situation, and the evolution of a science module, is reported. Data originate from pre-post-module evaluation questionnaires for two cohorts of students (2011 and 2014). The questionnaires have remained the same over recent years (2009-2018). While the reliability of responses has not been determined, the fact that they are anonymous and online might suggest that the participants would not need to fabricate false responses. There are a number of different item styles contained in the questionnaire, for example, Likert scale items, opened-ended questions and short anecdotal paragraphs.

Included is an item asking students to write down five words that describe their beliefs and attitudes concerning the forthcoming module (pre-questionnaire) and similarly in the post-questionnaire, where they reflect on their experiences during the module. Word clouds are generated from these words. It was during our interrogation of these word clouds that we began to consider more carefully the potential changes in beliefs and attitudes - changes that might have been a consequence of changing both the contents and underpinning philosophy of the module.

\section{Word clouds}

According to McNaught and Lam (2010), a word cloud is a visual representation of words where the more times a word appears in a text, the bigger that word is represented in the word cloud diagram. They caution, however, that while this tool is a useful initial way to present information, it is not equivalent to traditional content analysis. Our intention with the word cloud instrument was not to use it as a standard research tool, but rather to guide us towards gleaning an insight into students' thinking and feelings about the module. In this study, the word cloud tool is a web-based application, Wordle (Feinberg 2014). Participants wrote down five single words that described their feelings and/or beliefs about science before and after completing the module. Using only single words avoided some of the criticisms of using word clouds, for example, the individual words are not considered out of context. However, participants might still have written down the exact same word, but have a personally different nuanced understanding of the word (McNaught \& Lam 2010).

Data from survey questionnaires are used to illustrate and support claims of positive change in pre-service FP students' views towards science.

\section{Participants}

Data reported in this study originate from two separate cohorts of pre-service FP teachers, namely the 2011 cohort $(n=52)$ and the 2014 cohort $(n=59)$. The participants in both cohorts had similar characteristics: all were female; all were in their twenties; all had not taken science beyond grade 9; and if they had, it was in the life sciences. Unlike the current (2018) cohort, they would have all completed their schooling in a handful of local urban high schools.

\section{Ethical considerations}

All online questionnaires were anonymous via the learning management platform, MOODLE. Students could opt out of having their responses used in our research by ticking a box in the first questionnaire item. While these responses were excluded from the research, all responses were considered when we evaluated the effectiveness of the module and considered student suggestions for improvements to the modules. Ethical clearance was obtained from the Human Ethics Committee Nelson Mandela Metropolitan University (Now Nelson Mandela University). Ethical clearance number: H15-EDU-CPD-001.

Much of the results and discussion section pertains to the content and delivery of the module. It is here, in the spirit of the SoTL, which this article hopes to open debate around about what should be included in, or excluded from, a preservice FP science module.

\section{Results and discussion}

The course underwent a metamorphic change over the space of 8 years (2006-2013) and for the past 4 years (2014-2017), annual changes have been minimal. Initially, 2006-2009, the approach was premised on the idea that the students did not like science because of their previous school experiences and 'dropped' it at the earliest opportunity (Grade 9). Consequently, they must lack content knowledge! Gradually over the years, while continuing with content, the focus and delivery methods began to change. The module's content ceased to consist of only subject content materials for students to learn and understand. The main aim now shifted towards attempting to change students' beliefs and attitudes towards science. Graduate FP science teachers should view themselves as scientists in the eyes of their classes. They should be confident in their content knowledge and have the ability to design and manage appropriate science activities. Ultimately, they must have a robust understanding of how science works.

\section{Word clouds}

The pre-module word clouds generated by each new cohort have differed little over the years. The initial 2011 word cloud (Figure 1) is as an example of a typical pre-module word cloud. McNaught and Lam (2010) remind us that word clouds are not a 'good enough' analysis tool in 
the traditional sense and that at best they provide initial information. These pre-module word clouds did, however, present us with a 'picture' of the affective status of the students at the start of the module.

These word clouds foregrounded words that might indicate large doses of apprehension amongst the participants, for example, nervous, confused, unsure, scared, difficult and complicated. A quote from a 2011 student exemplifies these feelings: 'I honestly expected it to be boring and I was petrified when I just heard the word science, ...' (Participant 36, FP Student, 2011). By way of comparison, the post-module word clouds for the 2011 and 2014 cohorts are presented in Figure 2 and summarised in Table 1.

Table 1 suggests that in 2011 the module succeeded in positively influencing students' attitudes towards science. A selection of anonymous student comments in the 2011-module-evaluation survey suggests that student selfefficacy was enhanced, for example, with respect to mastery experiences:

'I definitely thought it would be a challenge, but by learning what science is all about and then given the opportunity to practice and understand what we learnt was important.' (Participant 11, FP Student, 2011)

'with respect to the affective domain: 'This module changed my attitude towards science, in a positive way' (Participant 2, FP Student, 2011)

'I expected the worst but now at the end it is the complete opposite' (Participant 1, FP Student, 2011).

Good science teaching, however, needs to move beyond just an attitudinal change. While students may have become more positively inclined towards science, there was little acknowledgement of being better prepared and confident to tackle the teaching of science. Our cue to change the module came from Luehmann's (2007) article that suggests that if pre-service teachers have not personally experienced what it is that they are to teach, they tend to lack confidence to teach it. We were also becoming aware that students, during their school-based learning experiences, were struggling to integrate the different topics within the life skills programme. This challenge is not uncommon in current FP classrooms
(Beni et al. 2017). Feedback from students, based on their experiences of the 2014 version of the module (Table 1), highlighted three themes that were not present in 2011: confident, prepared and knowledgeable. Students' 2014 post-module comments suggest that the module was now improving their subject knowledge and confidence:

'Very exciting and was actively involved in the learning of science. Made me gain confidence and knowledge when it comes to science.' (Participant 5, FP Student, 2014)

'I underestimated science. It is actually fun and very interesting, I have learnt more now than my past 12 years of school.' (Participant 27, FP Student, 2014)

'I had no knowledge about all the science but now I do have more knowledge and a bigger insight on science.' (Participant 35, FP Student, 2014)

The change in emphasis of student responses between 2011 and 2014 begs the question: How did the module change during this period? In responding to this question, it might be informative to go back to the beginning, to 2006 .

\section{Module evolution}

The first 3 years of the module is best categorised as subject-content-matter-only approach. During the following period (2009-2010), a smattering of pedagogical content knowledge was included. This specialised knowledge was premised on a constructivist approach, thus integrating common science misconceptions into the pre-service teachers' repertoire. This era of the module's evolution started to exhibit scholarly teaching. There was a shift from simply teaching content to including research aspects of science teaching. The focus on content and pedagogical content knowledge was an improvement, but we were still getting unsatisfactory post-module student comments. It was around

\begin{tabular}{ll}
\multicolumn{2}{l}{ TABLE 1: Dominant words in the 2011 and 2014 word clouds. } \\
\hline $\mathbf{2 0 1 1}$ & $\mathbf{2 0 1 4}$ \\
\hline Interesting & Excited \\
Fun & Confident \\
Exciting & Enthusiastic \\
Practical & Prepared \\
Cool & Knowledgeable \\
\hline
\end{tabular}

Note: The terms in bold were 'new' themes that were not present in the 2011 cohort's word cloud.

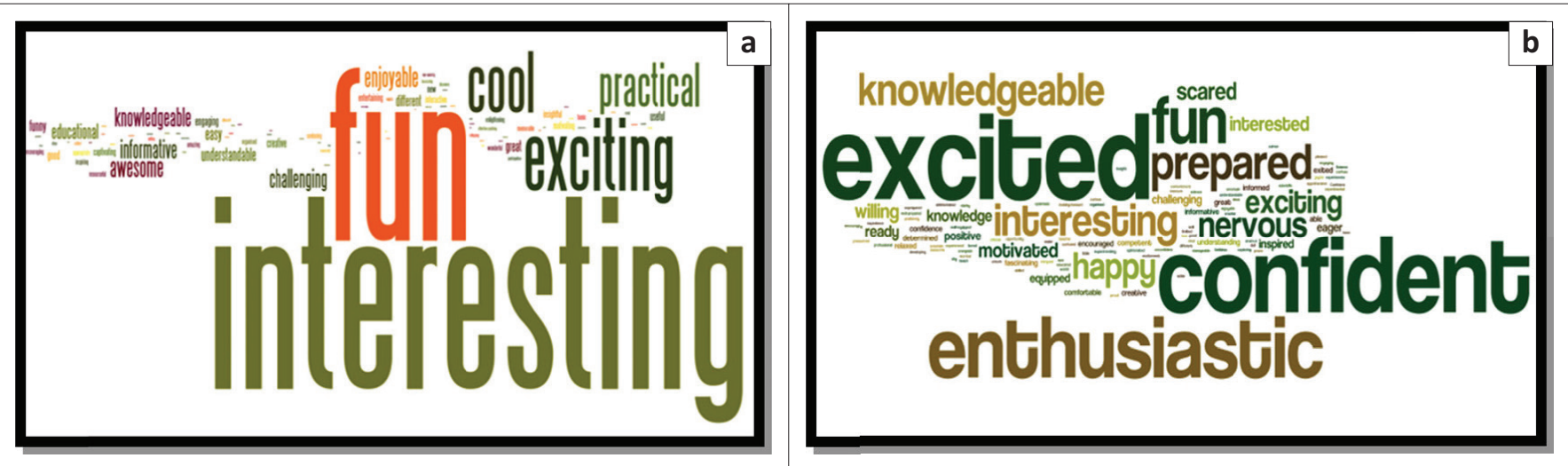

FIGURE 2: The word clouds generated by the (a) 2011 and (b) 2014 cohorts on completion of the module. 
this time that the draft national school curriculum documents started appearing for general comment. Based on these, we started introducing the idea of authentic investigations. During authentic investigations, we experienced the following student response: 'So what is the right answer?' This 'rightanswer focus' is common when dealing with pure content and factual knowledge; however, this is not the essence of investigations. Luehmann (2007:830-831) says that 'School science that values creativity, embraces multiple right answers, and is open-ended and messy is an unfamiliar image to many future science teachers, ...' It was during this period that we began to entertain possible ways to address this skewed idea of investigations. A shift in focus occurred with the introduction of tenets taken from the NOS, for example, that science is tentative and based on theories that need to have the potential to be falsifiable. In addition, we started embracing Johnston's (2005) idea that the early years of science should focus on explorations rather than the more formulaic investigations which are undertaken in the intermediate phase.

The next period of module evolution (2010-2012) introduced the idea of scientific literacy. During this period, two approaches dominated, the Predict-Explain-Observe (Liew \& Treagust 1995), and the use of science notebooks (Nesbit et al. 2004). Science notebooks provide a fruitful route to follow in the teaching of science in the primary school. In this pedagogy, students are exposed to Toulmin's writing frame to support a scientific argument.

In attempts to address students' perceived aversion to science, we introduced numerous activities that foregrounded the 'magic' of science. Initially (2011), we did the impressive 'stuff': the collapsing can, popping balloons, etc., in the format of demonstrations of discrepant events, mainly delinked from understandable explanations of the science involved. Students came to the lectures for the entertainment, but still were not overly enamoured by science. Roth (2014) claims that low-quality lessons are ones where there is 'activity for activity's sake'. While we might not have set out to do activities for activities sake, we could not deny that we aimed to entertain and capture student interest via science spectaculars.

It was during 2012-2013 that we started to deliberate on what philosophical and conceptual ideas should underpin a science education module, starting from the premise that the module should address three broad pillars or constructs, namely science teacher identity, science teacher self-efficacy and the NOS. The 2018 version of the module consists of eight units, with the first of these, 'So what is science?', being allocated a dominant $30 \%$ of the module's time. This first unit has begun to include the construct of multiple knowledges by including in the title 'and whose science is it?' This unit forms the foundation of the module, while the remaining seven units (Appendix 1) are each allocated $10 \%$ of the available time.

\section{Module design - The entrée}

'What is science?' is the unit that sets the tone for the rest of the module. The remaining units, while stand-alone, rely on this first unit for laying the groundwork to enable an understanding of how and where science fits into the rest of the module. The module starts with an understanding of where the students are coming from. They are nervous, confused, unsure, scared and fear the difficult and complicated terrain into which they are venturing (Figure 1). Various activities, designed to convince students that they can do science, are undertaken. Hands-on activities designed to capture attention and focus on discrepant events are followed by carefully choreographed open-ended questions designed to elicit student explanations and theories. By way of example, two tried and tested classic activities are pulling a piece of paper out from under a glass of water (to illustrate inertia), and an activity that illustrates how water increases in volume by approximately a 1000 times when it changes phase (illustrating phase change). These activities link directly to the everyday experience of inertial reel seatbelts and the dangers of dunking wet potato chips into hot oil.

Once one has an engaged audience, albeit a captive one, we then move to encourage students to challenge their identity as 'scientists'. This activity, based on Chamber's (1983) 'draw a scientist' study, throws up the usual stereotypical sketches. After general banter that includes comments such as: so to be a scientist one must have no hair or poorly kept hair and have issues with eyesight, the discussion then turns to stereotypes and concludes with the single show-stopping question: 'Who of you drew yourself?' This is the first time that students entertain the idea that they are probably the first 'scientist' that children encounter at school. The responsibility is not lost on them. As a useful prompt to encourage students to take on their newly identified role as the scientist in their classrooms, they are shown their competition for the children's science learning. There are any number of videos to use in this activity. We currently choose the series, Nina and the Neurons (Bryan 2007) as it is both entertaining, from a visual perspective, and scientifically correct, which is an important, but often overlooked aspect when one choses popular media for teaching science. Interesting and useful pedagogical aspects for teaching science to young children are pointed out to students during the viewing.

Luehmann (2007) promotes story telling about ones' own participation in a particular context, as being able to impact on one's own identity and future actions. She claims that one should not underestimate the huge impact of a pre-service teacher's own school experiences. As such, during the initial weeks of the module, students write reflective paragraphs on their past science experiences and document their vision for themselves as FP science teachers.

\section{Module design - The main}

An issue with a science-content-only approach is that students, starting from an inadequate and insecure understanding of 
the science content, seek out the one correct answer. While the one correct answer is adequate for 'facts' and 'laws', it is inadequate for theories. Just as scientists offer their theories up for others to attempt to falsify, so should children be encouraged to offer their explanations for phenomena up for attempted falsification. In this way, students are exposed to two fundamental elements of science, both of which rely on the falsification construct. Scientific theories have the potential for falsification, if there is no potential for falsification, then it is something else, no better or worse than science, it is just not science. This is an important aspect of the module, firstly, it dispels the hegemony of science, and secondly, it allows for all manner of other beliefs to avoid being sacrificed on the altar of a science hegemony. By way of example: 'The moon is made of green cheese' qualifies as a scientific statement: it has the potential to be falsified. Humans have gone to the moon and thus the potential to falsify it exists. On the other hand, the statement 'God exists' is not falsifiable and, as such, does not qualify as a scientific statement. It may still, however, be considered by people to be a true statement, just not a scientific one. The dialogical approach that we promote in the module is best exemplified by the anecdote based on a science educationalist's experiences with his own child (Box 1).

Students engage with the story, encouraged to ask the child why he thinks that the robot changes as the car approaches. In other words, to encourage the child to theorise an explanation for, what is for him, a curious phenomenon. It is up to the teacher to attempt to falsify the child's theory. Students seldom offer something similar to the child's explanation, which is, 'It is the man in the little grey box, when he sees us coming and it is safe, he changes the light to green'. As an aside, I have yet to come across a robot, anywhere in the world, that does not have the ubiquitous grey control box in close proximity. This begs the question of the students: 'How might you attempt to falsify the child's theory?'

Thus, by choosing carefully selected examples, preferably based on the student's own life experiences, one can overtly teach the NOS and 'how science works' in an innovative and meaningful manner. How children learn science is analogous with how scientists 'work'. Once the link is established, the students' understanding of both the NOS and their understanding of how children learn science reaches a tipping point, where their science teaching pedagogy focuses on teaching science for understanding rather than rote learning. Students' comments from their anonymous questionnaire included:

BOX 1: Sample anecdote illustrating a child's scientific theory.

A child was riding one night in a car with his father. As they approached the robot, it turned green. What follows below, might have been the conversation:

Child (excitedly): The robots are all changing green as we get near. How does the robot know that we are getting near to it so that it can change green?

Father (authoritatively): There are sensor cables built into the road just before the robot, and as we drive over them, the weight of the car triggers the sensors and makes the robot change.

Child (softly and sadly): Okay
'I did not know how important it is to have an understanding of science in order to teach young FP children.' (Participant 45, FP Student, 2014)

'This module gave me new insight about science as a whole.' (Participant 7, FP Student, 2014)

'... let me think of how science is ...' (Participant 32, FP Student, 2014)

'It was interesting to see how to make learning of science fun and exciting as well as adaptable for the certain age groups.' (Participant 2, FP Student, 2014)

Luehmann (2007) suggests that a key aspect in transforming teachers into effective science teachers is to get them to experience investigations as learners themselves. The module exposes students to key constructs via appropriate FP science activities. Observation is a science process skill that is required in a number of areas in science. After experiencing the danger of believing that one can make unbiased observations, students are trained in how to develop both observational and investigative skills in young children, by experiencing practical hands-on activities themselves involving authentic investigations. By way of example, students do an activity named: 'Drops on the coin'. Students predict the maximum number of drops of water that can fit on the surface of a coin. This example uses the predictobserve-explain approach (Liew \& Treagust 1995). While linking to the NOS and process skills, students are cued into linking this with the development of fine motor skills in young children.

Once an idea of 'teacher as a scientist' is established, the challenge is to tackle the dearth in science content knowledge possessed by the students; however, tackling this from a subject topic approach reaped few, if any, rewards in the first few iterations (2006-2010) of the module. Beni et al.'s (2017) study found that FP teachers don't easily integrate science into the life skills programme because they are unsure of their own scientific understanding and/or simply cannot 'find' the science in the curriculum documents. This supports the premise underpinning the remaining seven module units, namely teaching content via appropriately integrated and FP relevant topics.

\section{Module design - The desert}

The 'hidden' science in the FP is often overlooked by teachers, possibly because they do not know what they should be looking for in the relevant documents. This suggests that science teacher educators should develop pre-service teachers' scientific content knowledge in appropriate areas and topics, as well as exploiting various innovative pedagogies that link the science to other areas of the life skills curriculum. Physical movement, dance, rhythm and poetry, all aspects where students appear not to hold the same trepidation that they hold for the science, need to be deployed in order to teach science. Acting out and singing the nursery rhyme 'twinkle, twinkle little star', while not being entirely scientifically correct, is a useful pedagogy to link other aspects of the 
curriculum to the hidden science. YouTube has interesting rhyming ditties that can link to a number of science topics, for example, the variables song (Baibel 2009) and 'The Dinosaur Song' (Derriman 2007). This particular clip, in addition to using song, dance and movement, is used to consider why dinosaurs became extinct (theories and NOS), linking present day animal conservation and dental structure linked to animal diets. Extensive use is made of cartoons (Keogh \& Naylor 1999) with students learning the science through the concept cartoons' misconceptions-based approach and developing a pedagogy to use concept cartoons in the area of language development and co-operative group work. All seven units (Appendix 1) focus on developing the students' science teaching identity and science teaching self-efficacy through a NOS framework. Each unit is stand-alone and includes appropriate subject content knowledge and, where possible, related children's misconceptions, which invariably are similar to the misconceptions held by the pre-service student teachers. The lectures and workshops involve hands-on activities, most of which are presented at an adult level, but are followed by discussions on how to adapt, if necessary, the activity to make it appropriate for young children. The science aspects are contextualised within the context of how a FP child might think, function and experience the science. Student comments suggest a degree of success here:

'I enjoyed how it integrated science with everyday life and that of the children.' (Participant 14, FP Student, 2011)

'The activities, linking it to how children think and reason and clearing their preconceived ideas.' (Participant 15, FP Student, 2011)

'It opened my eyes to ways of how a child thinks and ways to teach difficult things and make it easier for the children to understand.' (Participant 20, FP Student, 2014)

'When starting this module, I hated science on all levels, but while doing this module, it has opened my view to science and being able to participate in something that was previously boring.' (Participant 13, FP Student, 2011)

'I am now more confident in my knowledge of science, there was room for exploration and personal growth.' (Participant 39, FP Student, 2011)

One final element to the module is introducing the students to the community of practice within the SoTL. Students read and comment on selected readings from practitioner journals. Currently, we have found many short, two or three page articles written by teachers and science educationalists with respect to teaching science to younger children in journals such as Primary Science [Association for Science Education (ASE)].

\section{Conclusion}

If the teaching of science, particularly in the primary school, is not to be compromised, science teachers need to have a positive attitude towards science, sufficient confidence in their ability to teach it, and a high degree of confidence in their own content knowledge and understanding. In the absence of clearer guidelines on integration in the FP CAPS curriculum, and appropriate pedagogies to teach science, we argue that it is incumbent on the science education trainers to guide and assist prospective FP teachers to:

- view themselves as a competent science specialist

- empower them with sufficient content knowledge and skills to teach the curriculum, including authentic integration of science within the FP programmes

- have a robust understanding of the NOS such as to create a positive and authentic view of science in children.

By using an ongoing student feedback loop, within a longterm SoTL research-type study, it is possible to develop a single science method module that succeeds in developing FP teachers who will confidently teach science. It is hoped that, in the interest of the SoTL, this article might contribute to the debate that involves how best to prepare FP science teachers.

\section{Acknowledgements Competing interests}

The author declares that he has no financial or personal relationships that may have inappropriately influenced him in writing this article.

\section{Authors' contributions}

L.F.M. contributed solely to this article.

\section{Funding information}

This research received no specific grant from any funding agency in the public, commercial or not-for-profit sectors.

\section{Data availability statement}

Data sharing is not applicable to this article as no new data were created or analysed in this study.

\section{Disclaimer}

The views and opinions expressed in this article are those of the author and do not necessarily reflect the official policy or position of any affiliated agency of the author.

\section{References}

Akerson, V.L., Abd-El-Khalick, F. \& Lederman, N.G., 2000, 'Influence of a reflective explicit activity-based approach on elementary teachers' conceptions of nature of
science', Journal of Research in Science Teaching 37(4), 295-317. https://doi. science', Journal of Research in Science Teaching 37(4), 295-317. https://d
org/10.1002/(SICI)1098-2736(200004)37:4\%3C295::AID-TEA2\%3E3.0.CO;2-2

Avraamidou, L., 2014, 'Developing a reform-minded science teaching identity: The role of informal science environments', Journal of Science Teacher Education 25(7), 823-843. https://doi.org/10.1007/s10972-014-9395-y

Baibel (Producer), 2009, 'The variable song', viewed 16 November 2017, from https:// www.youtube.com/watch?v=hwU3YL_SD70.

Bandura, A., 1997, Self-efficacy: The exercise of control, W H Freeman, New York.

Beni, S., Stears, M. \& James, A., 2017, 'Foundation phase teachers' interpretation of the life skills programme with regard to the teaching of natural science', South African Journal of Childhood Education 7(1), a440. https://doi.org/10.4102/sajce. v7i1.440

Bosman, L., 2009, 'The value, place and method of teaching natural science in the foundation phase', MEd dissertation, Dept. Didactics, University of South Africa.

Bryan, K. (Director), 2007, Nina and the Neurons, BBC CBeebees, London. 
Chambers, D.W., 1983, 'Stereotypic images of the scientist: The Draw-a-Scientist Test', Science Education 67(2), 255-265.

Department of Basic Education, 2011, Curriculum and assessment policy statement grades R-3: Life skills, Department of Basic Education, Pretoria.

Derriman, B. (Writer), 2007, The Dinosaurs Song, viewed 16 November 2017, from https://www.youtube.com/watch?v=WOFOZO-VpcU.

Evans, R., 2015, 'Self-efficacy in learning science', in R. Gunstone (eds.), Encyclopedia of science education, pp. 961-964, Springer, Dordrecht. https://doi.org/10.1007/ 978-94-007-2150-0_421

Feinberg, J., 2014, Wordle, viewed 16 November 2017, from http://www.wordle.net/. Johnston, J., 2005, Early explorations in science, Open University Press, Maidenhead.

Keogh, B. \& Naylor, S., 1999, 'Concept cartoons, teaching and learning in science: An evaluation', International Journal of Science Education 21(4), 431-446. https:// doi.org/10.1080/095006999290642

Konstantopoulos, S. \& Chung, V., 2011, 'The persistence of teacher effects in elementary grades', American Educational Research Journal 48(2), 361-386. https://doi.org/10.3102/0002831210382888

Liew, C.W. \& Treagust, D.F., 1995, 'A predict-observe-explain teaching sequence for learning about students' understanding of heat and expansion of liquids', Australian Science Teachers' Journal 41(1), 68-71.

Luehmann, A.-L., 2007, 'Identity development as a lens to science teacher preparation', Science Education 91(5), 822-839. https://doi.org/10.1002/sce. 20209

Mansfield, C.F. \& Woods-McConney, A., 2012, 'I didn't always perceive myself as a "Science Person": Examining efficacy for primary science teaching', Australian Journal of Teacher Education 37(10), 37-45. https://doi.org/10.14221/ajte. 2012v37n10.5

Maurer, T.W. \& Law, D., 2016, 'The scholarship of teaching and learning in family science', Family Science Review 21(1), 2-17.
McNaught, C. \& Lam, P., 2010, 'Using Wordle as a supplementary research tool', The Qualitative Report 15(3), 630. https://doi.org/10.26536/FSR.2016.21.02.01

Nesbit, C.R., Hargrove, T.Y., Harrelson, L. \& Maxey, B., 2004, 'Implementing science notebooks primary grades', Science Activities: Classroom Projects and Curriculum Ideas 40(4), 21-29. https://doi.org/10.3200/SATS.40.4.21-29

Palmer, D., 2006, 'Sources of self-efficacy in a science methods course for primary teacher education students', Research in Science Education 36(4), 337-353. https://doi.org/10.1007/s11165-005-9007-0

Roth, K.J. (ed.), 2014, Elementary science teaching, vol. 2, Taylor \& Francis, New York.

Sandholtz, J.H. \& Ringstaff, C., 2014, 'Inspiring instructional change in elementary school science: The relationship between enhanced self-efficacy and teacher practices', Journal of Science Teacher Education 25(6), 729-751. https://doi.org/ 10.1007/s10972-014-9393-0

Slavin, R.E., Lake, C., Hanley, P. \& Thurston, A., 2014, 'Experimental evaluations of elementary science programs: A best-evidence synthesis', Journal of Research in Science Teaching 51(7), 870-901. https://doi.org/10.1002/tea.21139

Stroebel, L.C., Hay, J. \& Bloemhoff, H.J., 2017, 'Needs and challenges of Foundation Phase life skills teachers in delivering physical education: Jack of all trades and master of none?' South African Journal for Research in Sport, Physical Education master of none?' South African
and Recreation 39(3), 163-177.

Tschannen-Moran, M., Hoy, A.W. \& Hoy, W.K., 1998, 'Teacher efficacy: Its meaning and measure', Review of Educational Research 68(2), 202-248. https://doi.org/ $10.2307 / 1170754$

Woolhouse, C. \& Cochrane, M., 2010, 'Now I think of myself as a physics teacher': Negotiating professional development and shifts in self-identity', Reflective Practice 11(5), 607-618. https://doi.org/10.1080/14623943.2010.516972

Zangori, L., Forbes, C.T. \& Biggers, M., 2013, 'Fostering student sense making in elementary science learning environments: Elementary teachers' use of science curriculum materials to promote explanation construction', Journal of Research in Science Teaching 50(8), 989-1017. https://doi.org/10.1002/tea.21104 


\section{Appendix 1: The seven units}

- Planet Earth and beyond: Focus on children's ideas of day and night, seasons, phases of the moon, eclipses.

- Weather: Focus on cause and effect, for example, the leaves are falling therefore winter is coming.

- Life processes: Focus on applying 'rules', for example, what characterises something as living?

- Fossils, dinosaurs, evolution and other theories: Focus on theories and current Earth sustainability challenges.

Beni et al. (2017) noted that physics and chemistry were seldom, if ever, attempted in the FP, and the final three units of the module attempt to address this challenge:

- Static and basic electricity (with a smattering of magnetism): Focus on simple electrical circuits, electrical safety.

- Energy and toys: Focus on using everyday toys to illustrate various energy constructs.

- Force, pressure and centre of gravity: Focus on centre of gravity activities relating these to assist young children to develop an awareness of their own balance. 